\title{
Synthesis of Ermanin, 5,7-Dihydroxy-3,4'-dimethoxyflavone from Kaempferol, 3,5,7,4'-Tetrahydroxyflavone with Two $O$-Methyltransferases Expressed in $E$. coli
}

\author{
Bong Gyu Kim, Hojung Kim, Jeong Ho Kim, Yoongho Lim, and Joong-Hoon Ahn* \\ Division of Bioscience and Biotechnology, Bio/Molecular Infonmatics Center, Konkuk University, Seond 143-701, Korea \\ "E-mail:jhahn@konkuk.ac.kr \\ Received December 9, 2005
}

Key Words : Ermanin, Kaempferol, $O$-Methylation

Enzymatic modifications of natural compounds have been drawn attention because they provide regioselectivity and chiral selectivity, which are hardly achievable with chemical synthesis. ${ }^{1,2}$ Using a mobilized enzyme or a whole cell containing a particular gene delivers useful tools for modification of natural compounds. In addition, using a whole cell, known as biotransfonmation, has advantage of saving expensive cofactors.

Flavonoids and alkaloids are secondary metabolites produced mainly in plants. ${ }^{3}$ Their bjological activities have an impact on human health ${ }^{4}$ so that they serve as target molecules to develop new drugs. One of common modification reactions found in these two groups of compounds is $O$-methylation due to free hydroxyl groups. various $O$ methylation reactions have been reported and a number of genes ( $O$-methyltransferases: OMTs) that medicated $O$ methylation have been cloned and characterized. ${ }^{5}$ Some of OMTs that use flavonoids as substrates are highly specific and thus they could be used for the regioselective modification of flavonoids. $O$-methylation of flavonoids resulted in reduction of chemical reactivity and increase of antimicrobial activity. ${ }^{5}$ So far, $O$-methylated flavonoids have been mainly isolated from plants, ${ }^{6}$ which could be a limitation for biological assays. Kaempferol (3,5,7,4'-tetrahydroxyflavone) is one of commonly found flavonoids in nature. Even though several biological activities of kaempferol have been established, its dimethoxy form, ermanin (5,7-dihydroxy-3,4'dimethoxyflavone) was known to have several activities including antiviral, ${ }^{7}$ anti-inflammatory, ${ }^{8}$ cytotoxic, ${ }^{9}$ and antibacterial activity. ${ }^{6}$ Lists of its biological activity might be extended if large amount of emmanin is supplied.

Previously, we cloned and characterized two OMT genes, $S O M T-2$ (soybean $O$-methyltransferase-2) ${ }^{10}$ and ROMT-9 (rice $O$-methyltrasnferase-9). ${ }^{11}$ The transgenic $E$. col $i$ expressing SOMT-2 transferred a methyl group to 4-hydroxy] group of flavonoids. ROMT-9 expressed in $E$. col $i$ showed different regioselectivity depending on the availability of 3'hydroxyl groups. It transferred a methyl group to 3'hydroxyl group if flavonoids have 3 -hydroxyl group. But, when 3'-hydroxyl group is not present, it methylated a 3hydroxyl group. Here we report the biological synthesis of ermanin from kaempferol with two OMTs expressed in $E$. coli.

ROMT-9 and SOMT-2 were cloned in one expression vector $^{12}$ and both proteins were induced from $E$. coli containing both ROMT-9 and SOMT-2 by adding IPTG at $100 \mu \mathrm{M}$. In addition, ROMT-9 and SOMT-2 were induced separately from $E$. coli containing either ROMT-9 or SOMT2. After $4 \mathrm{hr}$ induction, the cells from each culture were harvested and resuspended in LB containing ampicillin (50 $\mu \mathrm{g} / \mathrm{mL}) . \quad 100 \mu \mathrm{M}$ of kaempferol $\left(3,5,7,4^{4}\right.$-tetrahydroxyflavone) was added. The mixture was further incubated for 15 hrs at $28{ }^{\circ} \mathrm{C}$. Analysis of culture filtrates from three reactions using high perfomance liquid chromatography $(\mathrm{HPLC})^{9}$ revealed that kaempferol was converted into a new product which had different HPLC retention time from kaempferol itself. ROMT-9 produced a new peak at 15.2 $\mathrm{min}$ (Fig. IB) and SOMT-2 produced a new peak at $19.9 \mathrm{~min}$

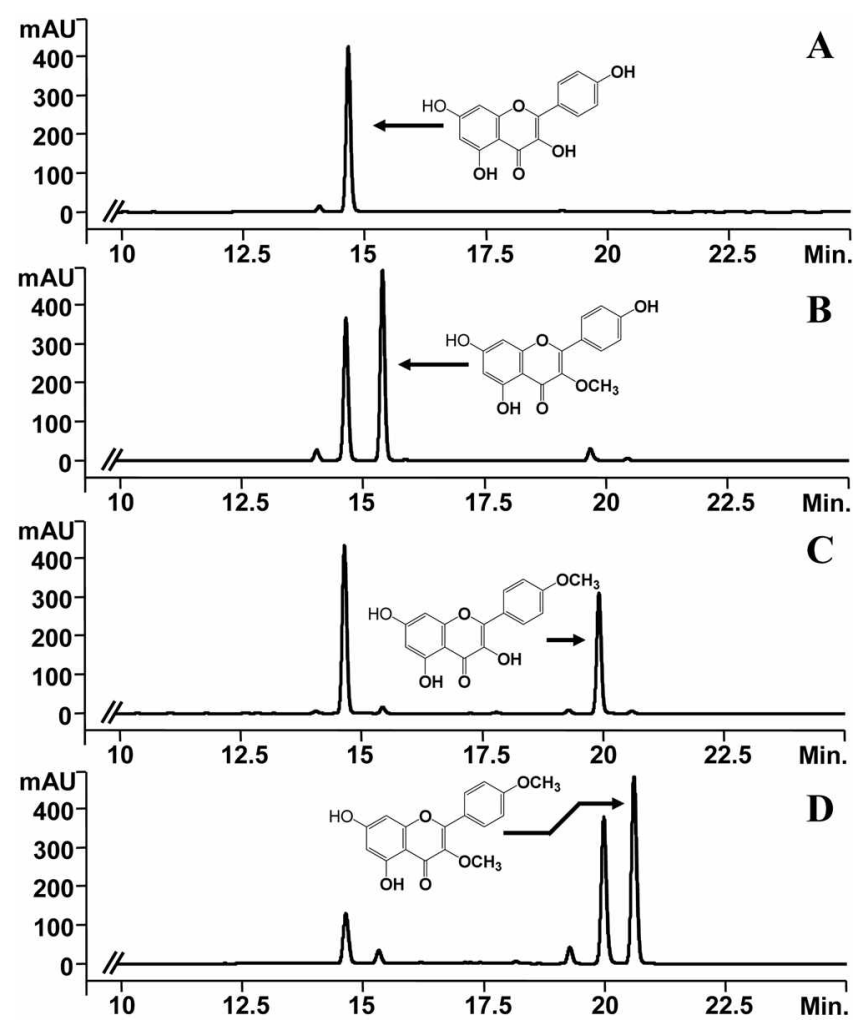

Figure 1. HIPLC analysis of kaempferol reaction products with SOMT-2 and ROMT-9. A, authentic kaempferol; B, reaction product of kaempferol with ROMT-9; C, reaction product of kacmpferol with SOMT-2; D, reaction product of kacinpferol with SOMT-2 and ROMT-9 
Table 1. The assignments of the NMR data of the metabolite of kaempferol produced by SOMT-2 and ROMT- 9<smiles>COc1ccc(-c2oc3cc(O)cc(O)c3c(=O)c2OC)cc1</smiles>

\begin{tabular}{ccrcc}
\hline position & $\delta$ of $^{\prime} \mathrm{H}$ & $\delta$ of $^{\prime \prime} \mathrm{C}$ & HMBC & NOESY \\
\hline 2 & - & 155.0 & - & - \\
3 & - & 139.1 & - & - \\
4 & - & 177.8 & - & - \\
5 & - & 161.1 & - & - \\
6 & $6.22(\mathrm{~d} ; 2.0)$ & 98.3 & $\mathrm{C}-5, \mathrm{C}-7, \mathrm{C}-8, \mathrm{C}-10$ & - \\
7 & - & 164.2 & - & - \\
8 & $6.45(\mathrm{~d} ; 2.0)$ & 93.6 & $\mathrm{C}-6, \mathrm{C}-7, \mathrm{C}-11$ & - \\
9 & - & 156.3 & - & - \\
10 & - & 104.3 & - & - \\
$3-0 \mathrm{OH} 3$ & $3.76(\mathrm{~s})$ & 59.6 & $\mathrm{C}-3$ & $\mathrm{H}-2^{+}$ \\
$1^{\prime}$ & - & 113.8 & - & - \\
$2^{\prime}$ & $8.02(\mathrm{~d} ; 9.0)$ & 129.9 & $\mathrm{C}-2, \mathrm{C}-4^{\prime}$ & $\mathrm{H}-3^{\prime}, 4^{\prime}-\mathrm{OCH} 3$ \\
$3^{\prime}$ & 7.13 (d; 9.0$)$ & 122.1 & $\mathrm{C}-1^{+}$ & $\mathrm{H}-2^{\prime}, 3-\mathrm{OCH}^{+}$ \\
$4^{\prime}$ & - & 161.2 & - & - \\
$4^{\prime}-\mathrm{OCH} 3$ & $3.84(\mathrm{~s})$ & 55.3 & $\mathrm{C}-4^{+}$ & $\mathrm{H}-3^{+}$ \\
\hline
\end{tabular}

(Fig. 1C) while two reaction products appeared from the reaction with $E$. coli expressing both ROMT-9 and SOMT-2 (Fig. 1D). One of them had the same retention time with the reaction product of ROMT-9. The peak at 20.6 min was likely to be a dimethylated product. The structure of this compound was clarified by NMR experiments as described in Kim et $a l^{10}$ Each eluent containing the metabolite of kaempferol produced by SOMT-2 and ROMT-9 was collected twenty times on HPLC and evaporated under reduced pressure. The dried remnant was dissolved in ethylacetate, and the supematant was separated by centrifuge and evaporated again under reduced pressure. The final remnant was dissolved in dimethylsulfoxide-d6 for the NMR experiments such as ${ }^{1} \mathrm{H},{ }^{13} \mathrm{C}$ NMR, HMQC, HMBC, and NOESY. The complete assignment of the NMR data of the reaction product is listed in Table 1 . Two methoxy peaks were observed at both the ${ }^{1} \mathrm{H}$ NMR spectrum and the ${ }^{13} \mathrm{C}$ NMR spectrum: $3.76 \mathrm{ppm} / 59.6 \mathrm{ppm}$ and $3.84 \mathrm{ppm} / 55.3 \mathrm{ppm}$. The methoxy proton at $3.76 \mathrm{ppm}$ showed a nOe cross peak with $\mathrm{H}-2^{\prime}$ in NOESY and was long-range coupled to $\mathrm{C}-3$ in $\mathrm{HMBC}$. Therefore, it should be $3-\mathrm{OCH}_{3}$. Likewise, because the methoxy proton at $3.84 \mathrm{ppm}$ showed a nOe peak with $\mathrm{H}$ $3^{\prime}$ and long ranged coupling peak with C-4' in NOESY and $\mathrm{HMBC}$, respectively, the methylated position is $4-\mathrm{OH}$. As a result, the final structure of the reaction product was $3,4^{\prime}$ dimethoxy, 5,7-dihydroxyl kaempferol, which was regioselectively methylated product from kaempferol. Emanin was successfully synthesized from kaempferol with two transgenic $E$. coli.

Production of ermanin was monitored periodically for 128 hr. SOMT-2 and ROMT-9 was induced as above. The culture

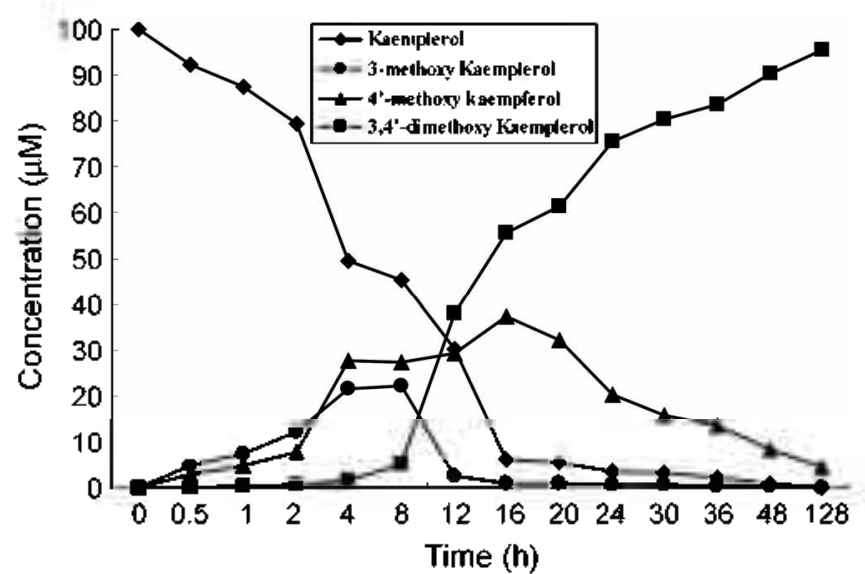

Figure 2. Production of ermanin using $E$. colt transformant expressing SOMT-2 and ROMT-9.

was collected periodically and the amounts of reactant and product quantifjed with HPLC. As shown in Figure 2, the amount of kaempferol continued to decrease over time and was completely metabolized after 24 hrs. In contrast, 3methoxy kaempferol increased in quality until $8 \mathrm{hrs}$ and 4methoxy kaempferol increased until $16 \mathrm{hrs}$. The ermanin appeared after $8 \mathrm{hrs}$ and continued to increase until $128 \mathrm{hrs}$. After 48 hrs incubation, more than $90 \%$ of kaempferol was converted into ermanin. Thus, $13.1 \mathrm{mg}$ of emmanin was obtained from $14.3 \mathrm{mg}$ of kaempferol with a yield of $91 \%$. This approach does not require an enzyme purification step and $S$-adenosyl-L-methionine as a cofactor. Thus, it may be suitable for the production of large amounts of emmanin.

Acknowledgements. This work was supported by a gaant of R01-2004-10688-0 (KOSEF) and KRF 2004-F00019 (KRF).

\section{References}

I. Raadt, A. D.; Griengl, H. Curr. Opin. Biotechnol. 2002, I3, 537.

2. Lee, P. H.; Kim, H.; Lee, K.; Dong, S.; Kim, S.; Kim, H.; Kim, H.; Lee, M.; Shim, E.; Lee, S.; Kim, M.; Han, M.; Noh, K.; Sridhar, M. Bull. Korean Chem. Soc, 2004, 25, 1687.

3. Wink, M. Introduction in Funtions of Plant Secondary Metabolites and Their Exploitation in Biotechnology, Wink, M., Ed.; CRC Press: Boca Raton, 1999; p I.

4. Middleton, E., J.; Kandaswami, C.; Theoharides, T. C. Pharnocol Rev: $2000,52,673$.

5. Ibrahim, R. K.; Bruneau, A.; Bantignies, B. Plant Mol. Biol. 1998. 36,1 .

6. Murillo, J. I.; Encarnacion-Dimayuga, R.; Malmstrom, J.; Christophersen, C.; Franzblau, S. G. Fitoteropia 2003, 74, 226.

7. Robin, V.; Boustie, J.; Amoros, M.; Girre, L. Pharn. Pharmacol. Comm. 1988, 4,61.

8. Martinez, J.; Silvan, A. N.; Abad, M. J.; Bermejo, P.; Villar, A.; Sollhuber, M. J. Nat. Prod. 1997, 60, 142.

9. Banskola, A. H.; Tezuka, Y.; Prasain, J. K.; Matsushige, K.; Saiki, I.; Kadota, S. J. Nat. Prod. 1998, 61, 896.

10. Kim, D. H.; Kim, B. G.; Lee, Y.; Ryu, J. Y.; Lim, Y.; Hur, H.-G.; Ahn, J.-H. J. Biotech. 2005, 119, 155.

11. Kim, B. G; Lee, Y.; Hur, H.-G.; Lim, Y.; Ahn, J.-H. Photochem. $2006,67,387$.

12. Kim, B. G.; Shin, K. H.; Lee, Y,; Hur, H.-G.; Lim, Y.; Ahn, J.-H. Biotech, Letters 2005. 27, 1861. 